\title{
Warm-Air Advection Over Melting Sea-Ice: A Lagrangian Case Study
}

\author{
Cheng You ${ }^{1}$ (D) Michael Tjernström ${ }^{1} \cdot$ Abhay Devasthale $^{2}$
}

Received: 4 May 2020 / Accepted: 7 November 2020 / Published online: 17 December 2020

(c) The Author(s) 2020

\begin{abstract}
Observations from the 2014 Arctic Clouds in Summer Experiment indicate that, in summer, warm-air advection over melting sea-ice results in a strong surface melting feedback forced by a very strong surface-based temperature inversion and fog formation exerting additional heat flux on the surface. Here, we analyze this case further using a combination of reanalysis dataset and satellite products in a Lagrangian framework, thereby extending the view spatially from the local icebreaker observations into a Langrangian perspective. The results confirm that warm-air advection induces a positive net surface-energy-budget anomaly, exerting positive longwave radiation and turbulent heat flux on the surface. Additionally, as warm and moist air penetrates farther into the Arctic, cloud-top cooling and surface mixing eventually erode the surface inversion downstream. The initial surface inversion splits into two elevated inversions while the air columns below the elevated inversions transform into well-mixed layers.
\end{abstract}

Keywords Arctic · Entrainment · Inversion - Lagrangian · Moist and warm air intrusion

\section{Introduction}

The Arctic near-surface temperature has increased more than twice as fast as the global average in recent decades (Graversen et al. 2008; Francis and Vavrus 2012; Cohen et al. 2014). This phenomenon, known as Arctic amplification (Serreze and Francis 2006), has contributed to dramatic melting of Arctic sea-ice (Simmonds 2015), rapid decline of spring snow cover (Derksen and Brown 2012), thawing of permafrost (Lawrence et al. 2008), and continued retreat of Greenland's ice sheet (Tedesco et al. 2013). Although many of the individual processes contributing to Arctic amplification are understood, their relative importance and interactions are poorly known (e.g., Vihma 2014).

Cheng You

cheng.you@misu.su.se

1 Department of Meteorology and Bolin Centre for Climate Research, Stockholm University, Stockholm, Sweden

2 Remote Sensing Unit, Research and Development Department, Swedish Meteorological and Hydrological Institute, Norrköping, Sweden 
Several previous studies suggest that warm-and-moist-air intrusions (WaMAI) into the Arctic from the south significantly contribute to Arctic amplification (Woods and Caballero 2016; Johansson et al. 2017; Liu et al. 2018; Messori et al. 2018; Naakka et al. 2019a). Woods et al. (2013) found an increasing trend in winter WaMAIs and suggested that they were linked to synoptic weather systems held in place by high-pressure blocking to the east. Messori et al. (2018) associated significant warming across large areas of the central Arctic with WaMAIs and found that the fraction of low clouds was almost doubled during WaMAIs, exerting a $20 \mathrm{~W} \mathrm{~m}^{-2}$ surface net-longwave-radiation anomaly. Surface warming was hence induced not only by warm-air advection, but also by increased longwave emissivity of the lower atmosphere. This was also found by Kapsch et al. (2013, 2016), who also linked additional incoming longwave surface radiation to an earlier sea-ice melt onset and hence a lower September ice extent. Climatologically, cloudiness was increased by $30 \%$ during Arctic warm-air intrusions in Johansson et al. (2017), causing an additional radiative heating (up to $0.15 \mathrm{~K} \mathrm{~d}^{-1}$ ) of the atmosphere.

Many studies have used statistics to relate anomalies in sea-ice to preceding anomalies in meridional heat transport across some arbitrary high latitude (Graversen et al. 2008; Kapsch et al. 2013; Johansson et al. 2017). Moreover, they often used anomalies of the meridional heat flux across an arbitrary latitude as a metric to define WaMAIs and their warming capacity. Few studies have focused on the gradual effects of the air-mass transformation which changes the properties of the intruding air mass, ultimately causing the surface warming during WaMAIs.

Most WaMAI studies focus on winter, when solar radiation is small or zero and the surface temperature is free to respond to changes in the surface energy budget, but only a few explore the summer season. Komatsu et al. (2018) reported on a WaMAI over the Laptev Sea in 2013 using soundings as well as simulations and concluded that the warm air glided up over a polar dome of cold air, contributing to Arctic amplification by release of latent heat as clouds formed in the ascending air. Tjernström et al. (2015) reported on a strong WaMAI in the Siberian Sea in August 2014 during the Arctic Clouds in Summer Experiment (ACSE). They described the formation of a very strong surface-based temperature inversion and persistent fog as the warm air adjusted to the cold surface. Observations of the surface energy budget showed that enhanced positive surface net-longwave radiation and downward turbulent heat flux overcame attenuation of surface solar radiation by the fog, resulting in a positive surface net-energy-budget anomaly. Sotiropoulou et al. (2018) used idealized largeeddy simulations and concluded that advection of moisture, rather than of sensible heat, was critical to the positive surface net energy budget.

Almost all available observations from the summer central Arctic boundary layer revealed cloud-capped but well-mixed boundary-layer conditions (e.g., Tjernström et al. 2012; Sotiropoulou et al. 2014; Brooks et al. 2017), quite different from the stably stratified and often foggy conditions experienced in on-ice flow near the ice edge (Tjernström et al. 2019). It was therefore hypothesized that cloud-top cooling, along with surface mixing, eroded the surface inversion downstream and eventually the boundary layer transformed to the oftenobserved well-mixed cloud-capped state. However, the in situ character of the observations during ACSE prohibited an evaluation of the farther air-mass transformation over the ice, and from observations alone it was difficult to close the energy balance and to determine the relative contributions from advection, cloud formation, radiation, and turbulent mixing.

Most, if not all, field campaigns are Eulerian by default, and this shortcoming has been discussed by Pithan et al. (2018). Herein, we use a combination of trajectories, satellite products, and a reanalysis dataset to extend the local view from the observations on the icebreaker Oden during ACSE to a Lagrangian perspective. The questions we seek to answer here are: (1) What happens farther downstream; will the surface inversion erode and give way 
to a cloud-capped well-mixed boundary layer as hypothesized? (2) During ACSE the surface inversion remained quasi-stationary for about a week; what boundary-layer or larger-scale processes are mainly responsible for maintaining this very robust feature over time?

\section{Data and Method}

The warm and moist intrusion case explored here was observed from 30 July to 7 August 2014, as Oden was navigating in melting multi-year sea-ice in the East Siberian Sea. Oden was equipped with an extensive array of in situ and surface-based remote sensing instruments and also carried out 6-hourly soundings. ACSE was described in detail by Sotiropoulou et al. (2016), while the intrusion case was documented in Tjernström et al. (2015). Being shipborne, ACSE only observed the intrusion at a roughly constant distance from the Siberian coast, as it crossed the eastward track of Oden.

To complement the detailed local observations, we use a combination of air-mass trajectories, thermodynamic profiles, and cloud information from satellite sensors as well as reanalysis to expand the domain. We here use the ERA5 reanalysis (Hersbach et al. 2020), the latest reanalysis from the European Centre for Medium Range Weather Forecasts (ECMWF); surface weather (SHIP) observations and soundings from Oden, as well as the satellite data we use, have been assimilated in ERA5.

\subsection{Trajectory Calculation and Data Interpolation}

To explore both the origin and fate of the air masses, we calculated air-mass trajectories 2 days forward and 2 days backward from the location of Oden every $6 \mathrm{~h}$ (example shown in Fig. 1), using ERA5 wind fields and the algorithm from Woods et al. (2013). Along the tracks from the combined backward and forward trajectories, vertical profiles of temperature and humidity were interpolated from the Atmospheric Infrared Sounder (AIRS) version 6, level 3 daily pan-Arctic satellite product (Chahine et al. 2006; Susskind et al. 2014; Devasthale et al. 2016) at each 0.5-degree interval in latitude. We also interpolated cloud information from the second edition of the satellite-derived climate data record (CLARA-A2) AVHRR (Advanced Very High Resolution Radiometer) satellite product (Karlsson et al. 2017) and surface radiation from the Clouds and the Earth's Radiant Energy System (CERES) (Wielicki et al. 1996). From ERA5 we interpolated profiles of temperature, humidity, and their time tendencies, in conjunction with profiles of cloud water, all on model levels, as well as all the terms in the surface energy budget.

Using trajectories for an air-mass transformation study is complicated and only works well in barotropic flow, where the trajectories at different altitudes will be stacked on top of each other since the flow does not vary with height. Such ideal conditions, however, rarely exist and, for example, Komatsu et al. (2018) found that the boundary-layer air and free-tropospheric air had very different origins. Hence, a compromise is necessary, and focusing on the lower atmosphere physics, we therefore calculate trajectories using different receptor/departure heights, from 300 to $800 \mathrm{~m}$, every $100 \mathrm{~m}$ (Fig. 1). Vertical cross-sections from the surface to $2 \mathrm{~km}$ and surface fluxes are then interpolated along each of these trajectories and the final results are the average from this ensemble of trajectories. It is important to understand that, although cross-sections as presented will have altitude on one axis and latitude on the other, they are not spatial cross-sections valid at a given time. They instead represent the atmosphere 


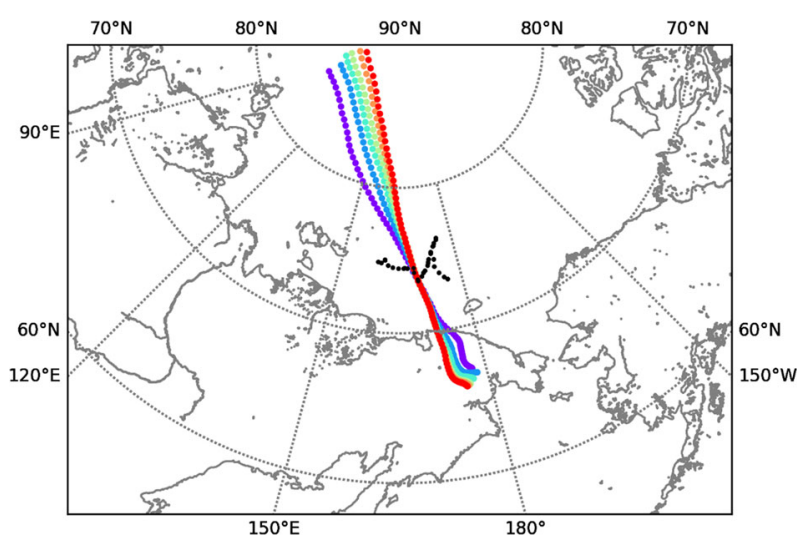

Fig. 1 Trajectories initialized at different heights, from $300 \mathrm{~m}$ (purple) to $800 \mathrm{~m}$ (red) at $100 \mathrm{~m}$ intervals above Oden on 6 August 2014. The location of Oden is marked with black dots

as it might appear if one could have followed along a trajectory in a constant level balloon releasing dropsondes along the way.

\subsection{Evaluation of Energy-Budget Terms}

To evaluate the different terms in the thermal energy equation, we will make use of the time tendency terms related to physical processes from ERA5, and interpolate them along the trajectories as previously described. The thermal energy equation is

$$
T_{\mathrm{t}}=\frac{\partial T}{\partial t}_{\mathrm{sw}}+\frac{\partial T}{\partial t} \mathrm{lw}_{\mathrm{w}}+\frac{\partial T}{\partial t}_{\mathrm{LH}}+\frac{\partial T}{\partial t} \mathrm{TSH}
$$

where the hourly-mean temperature tendency $T_{\mathrm{t}}$ of the air mass in a Lagrangian sense is cumulatively contributed by the local heating/cooling from shortwave and longwave radiation $\left(\frac{\partial T}{\partial t}_{\mathrm{sw}} ; \frac{\partial T}{\partial t} \mathrm{lw}_{\mathrm{w}}\right)$, release of latent heat at cloud formation $\left(\frac{\partial T}{\partial t} \mathrm{LH}_{\mathrm{H}}\right)$, and vertical turbulent heat transport $\left(\frac{\partial T}{\partial t} \mathrm{TSH}\right)$ at every point along the trajectory. Here, the release of latent heat is estimated from the tendency of the specific humidity due to parameterized processes, also provided as an output in ERA5

$$
\frac{\partial T}{\partial t} \mathrm{LH}=-L_{\mathrm{v}} \frac{\partial q}{\partial t}=-L_{\mathrm{v}}\left(\frac{\partial q^{*}}{\partial t}+\frac{\partial q^{\prime}}{\partial t}\right)
$$

where $\frac{\partial q}{\partial t}$ is the time tendency of specific humidity due to phase transition $\left(\frac{\partial q^{*}}{\partial t}\right)$ and turbulent process $\left(\frac{\partial q^{\prime}}{\partial t}\right)$ and $L_{\mathrm{v}}$ is latent heat of vapourization. Latent heat release is evaluated by (2) instead of directly by $-L_{v} \frac{\partial q^{*}}{\partial t}$, given that $\frac{\partial q^{*}}{\partial t}$ is not available from ERA5.

To offset the extra heat $\frac{\partial q^{\prime}}{\partial t}$ introduced in Eq. 2, one more term, turbulent latent heat $\left(\frac{\partial T}{\partial t}{ }_{\mathrm{TLH}}=L_{\mathrm{V}} * \frac{\partial q^{\prime}}{\partial t}\right)$ is added into Eq. 1. Then, the new version of Eq. 1 is

$$
T_{t}=\frac{\partial T}{\partial t}_{\mathrm{sw}}+{\frac{\partial T}{\partial t}{ }_{\mathrm{lw}}}-L_{\mathrm{v}}\left({\frac{\partial q^{*}}{\partial t}}^{*}+\frac{\partial q^{\prime}}{\partial t}\right)+\frac{\partial T}{\partial t}_{\mathrm{TSH}}+L_{\mathrm{v}} \frac{\partial q^{\prime}}{\partial t}
$$



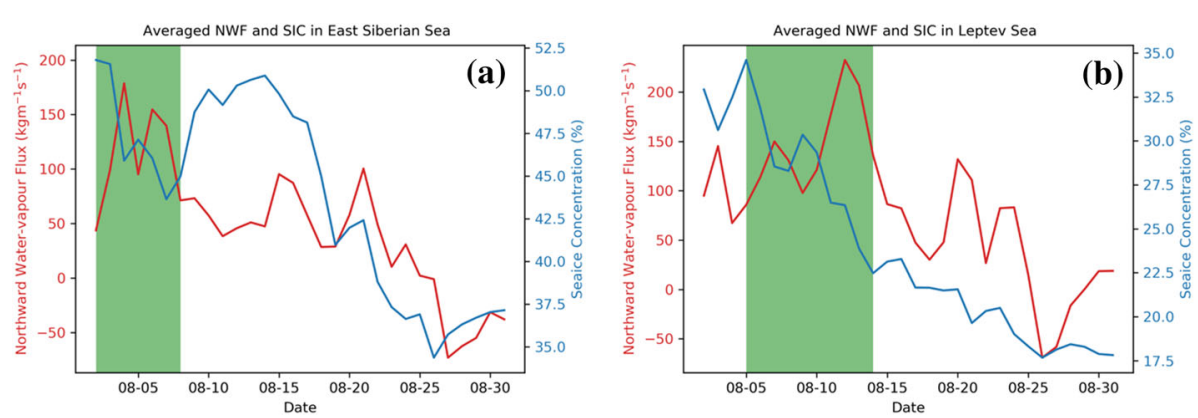

Fig. 2 Time series of northward water-vapor flux (NWF, Unit: $\mathrm{kg} \mathrm{m}^{-1} \mathrm{~s}^{-1}$ ) and sea ice concentration (SIC, Unit: \%) over East Siberian Sea (a) and Laptev Sea (b) in August 2014. The time period when WaMAI happened is highlighted in green

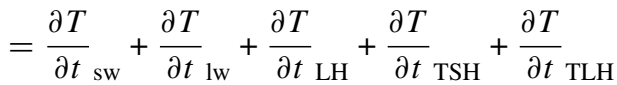

$$
\begin{aligned}
& =\frac{\partial T}{\partial t}_{\mathrm{sw}}+{\frac{\partial T}{\partial t}{ }_{\mathrm{lw}}}+{\frac{\partial T}{\partial t}{ }_{\mathrm{LH}}}+\frac{\partial T^{\prime}}{\partial t} \text {. }
\end{aligned}
$$

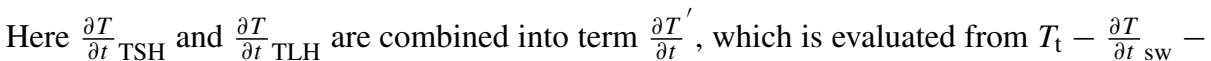
$\frac{\partial T}{\partial t}{ }_{\mathrm{lw}}-\frac{\partial T}{\partial t} \mathrm{LH}^{*}$

\section{Results}

\subsection{Large-scale Atmospheric Setting}

The East Siberian and Laptev Seas were exposed to an inflow of warm and moist air from late July through a large part of August 2014 - strongest in the first weeks and tapering off with time. During this time, average sea-ice concentration decreased by about $20 \%$ (Fig. 2). We used a northward water-vapour flux to indicate the strength of the WaMAI. During 3-5 August, the centre of WaMAI was located over the East Siberian Sea, but started to move westward from 6 August; after about 8 August the WaMAI remained stationary over the Laptev sea. The WaMAI was forced by a blocking high-pressure system near the Bering Strait (Tjernström et al. 2015) and occurred on the western side of this circulation system (Fig. 3). The centre of this blocking remained near the Bering Sea during 3-5 August (Fig. 3a), but then expanded poleward and on 7 August extended across the pole (Fig. 3b). As the centre of the blocking propagated northward, the warm and moist air also intruded farther into the Arctic (Fig. 3e). Later the blocking high shifted slightly westward (Fig. 3c) and correspondingly the core of the warm-and-moist air advection also switched from being located east of the New Siberian Islands to their western side (Fig. 3f).

Oden was located to the east of the New Siberian Islands, gradually working its way eastward. On 6 August, Oden entered into the centre of the blocking high-pressure system, where it was still warm but much drier due to the subsidence (Tjernström et al. 2015). Thus, Oden only observed a week-long WaMAI episode gradually tapering off. However, Oden only intersected with the prolonged WaMAI for a limited time and then moved to the east, while the WaMAI moved westward. Thus, the statements in Tjernström et al. (2015) about 
(a) $850 \mathrm{hPa}$ Temperature $\left({ }^{\circ} \mathrm{C}\right)$ on 2014-08-04

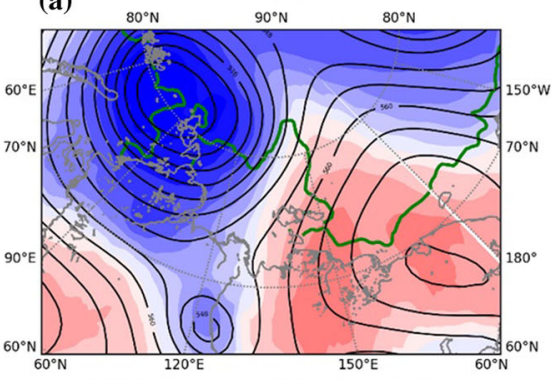

(b) $850 \mathrm{hPa}$ Temperature $\left({ }^{\circ} \mathrm{C}\right)$ on $2014-08-07$

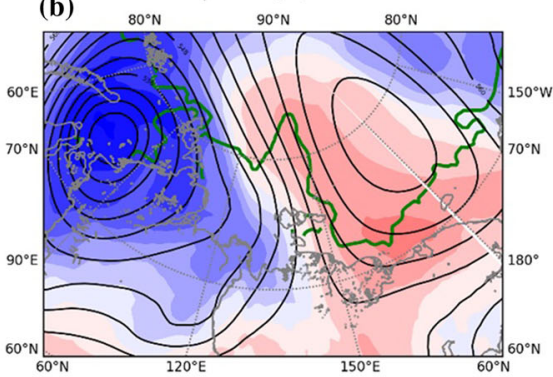

(c) $850 \mathrm{hPa}$ Temperature $\left({ }^{\circ} \mathrm{C}\right.$ ) on 2014-08-12

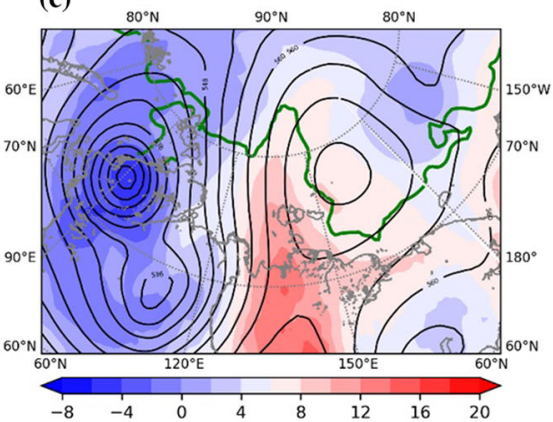

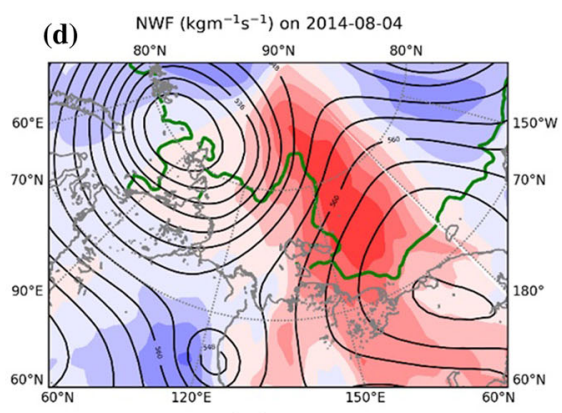
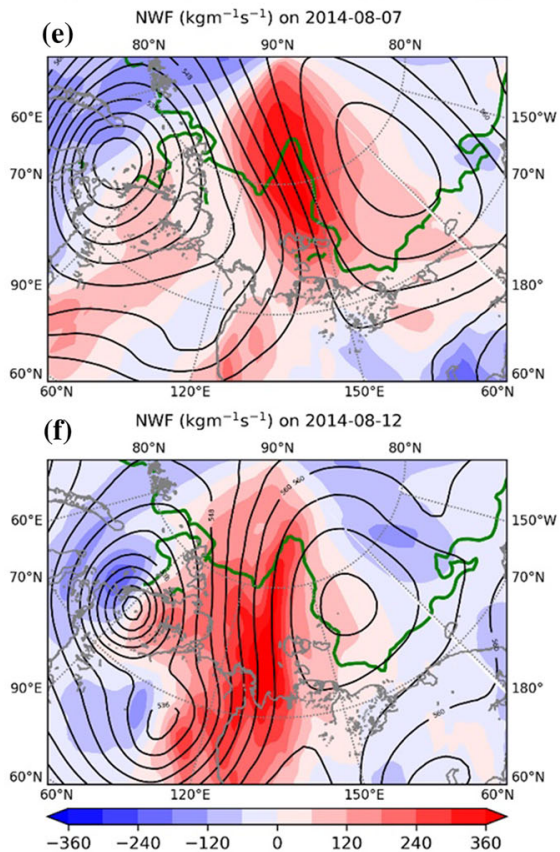

Fig. 3 In (a-c) colour shaded 850 -hPa temperature $\left({ }^{\circ} \mathrm{C}\right)$ and $(\mathbf{d}-\mathbf{e})$ northward water-vapor transport $\left(\mathrm{kg} \mathrm{m}^{-1}\right.$ $\mathrm{s}^{-1}$ ) with overlaid solid contours of the 500-hPa geopotential height (gpm), for (a, d) 4 August, (b, e) 7 August and (c, f) 12 August, 2014

different phases of the intrusion was more a result of Oden's changing position relative to the blocking high than a manifestation of a temporal development of the intrusion.

\subsection{Comparison Between the Atmospheric Infrared Sounder and ERA5}

In Fig. 4, we first compare profiles from AIRS and ERA5 to soundings from Oden. ERA5 mostly captures the structure of temperature profiles in the warm-air advection; AIRS also matches the soundings quite well, except on 4 August when the maximum temperature in the surface inversion observed by AIRS is nearly $5{ }^{\circ} \mathrm{C}$ lower than in the soundings. However, AIRS products have a poorer vertical resolution, with only six levels below $500 \mathrm{hPa}$. The agreement with the soundings is generally poorer for humidity than for temperature, for both ERA5 and AIRS; the latter especially fails to capture the humidity structure on both 3 and 
4 August. Apparently, ERA5 performs better than AIRS during this MaWAI case. However, since the irradiances from AIRS are assimilated directly in ERA5, and not the retrieved profiles, it is difficult to assess the similarities and discrepancies. It may simply be that the weight of the sounding information is higher in the assimilation, given that there are so few soundings in the Arctic and normally none over the Arctic Ocean. Comparing results from the ECMWF operational data assimilation, essentially the same as in ERA5, for two other field campaigns with and without assimilation of the soundings, Naakka et al. (2019b) showed a large impact from assimilating soundings.

\subsection{The MaWAI Mean Structure from Satellite}

Earlier than 6 August, the trajectories indicate that WaMAIs are not strong enough to penetrate north of $80^{\circ} \mathrm{N}$. Later, Oden moves into the blocking high, while the air mass moving poleward is dry. Therefore, for this study, we select the trajectory initiated at 0000 UTC on 6 August; cross-sections along trajectories initiated at 0600 UTC and 1200 UTC on 6 August are almost same. Oden is then located at $73.53^{\circ} \mathrm{N}, 169.49^{\circ} \mathrm{E}$. The trajectory tracks (Fig. 1) are relatively close together despite being at different heights. The direction of the air mass at each height changes from south-west to north-east in the vicinity of the coastline where a small trough is located. The wind rotates anticlockwise with height over the land, which signals cold advection. However, over the sea the flow rotates clockwise with height and fans out more, signalling warm advection.

Figure 5 shows the average of cross-sections from AIRS satellite products along all the trajectories in Fig. 1. The low spatial and temporal resolutions of the AIRS products filter out many details but the initial surface inversion in both temperature and specific humidity at the coastline is seen already from around $70^{\circ} \mathrm{N}$. North of $70^{\circ} \mathrm{N}$, the inversion altitude increases dramatically and reaches a quasi-constant height ( $925 \mathrm{hPa}$, approximately $700 \mathrm{~m}$ ) at $72-73^{\circ} \mathrm{N}$, allowing a new boundary layer to develop. The temperature in the inversion is decreasing gradually, probably because of the turbulent mixing which will be discussed in Sect. 3.5. The cross-section of specific humidity follows a similar development as temperature, with very moist air above the inversion-a quite common situation in the summer Arctic (e.g., Tjernström 2005; Sedlar et al. 2012). The moisture in the inversion is also gradually decreasing, likely due to formation of cloud water, some of which precipitates out. North of $78^{\circ} \mathrm{N}$ the capping inversion becomes sporadic and the boundary-layer temperature decreases as the elevated inversion disappears, possibly due to a reduction in low clouds.

Results from the CLARA products interpolated to the trajectory locations are shown in Fig. 6. Around Oden's location, the CLARA products indicate a relatively low cloud fraction, much lower than the in situ observation. It is possible that AVHRR has a problem distinguishing low clouds from the sea-ice. As the warm air is advected farther into the Arctic, the cloud fraction and cloud top quickly rise deepening the boundary layer (Fig. 6). In contrast to the cross-sections from AIRS (Fig. 5), this increase in cloud-top height continues north of $78-80^{\circ} \mathrm{N}$, to much higher altitudes than the capping inversion in the AIRS. Possibly, there may have been a higher cloud layer that shielded the lower boundary-layer cloud layer from the view of the AVHRR satellite passive sensors; satellite imagery indicates some higher clouds closer to the Pole (Tjernström et al. 2015, supplementary Fig. 1). Additionally, cloud tops are not observed directly but are derived from satellite measured cloud-top temperature along with a priori temperature profiles from a numerical model. Since the temperature soundings from ACSE are available for assimilation, a priori model profiles should have 

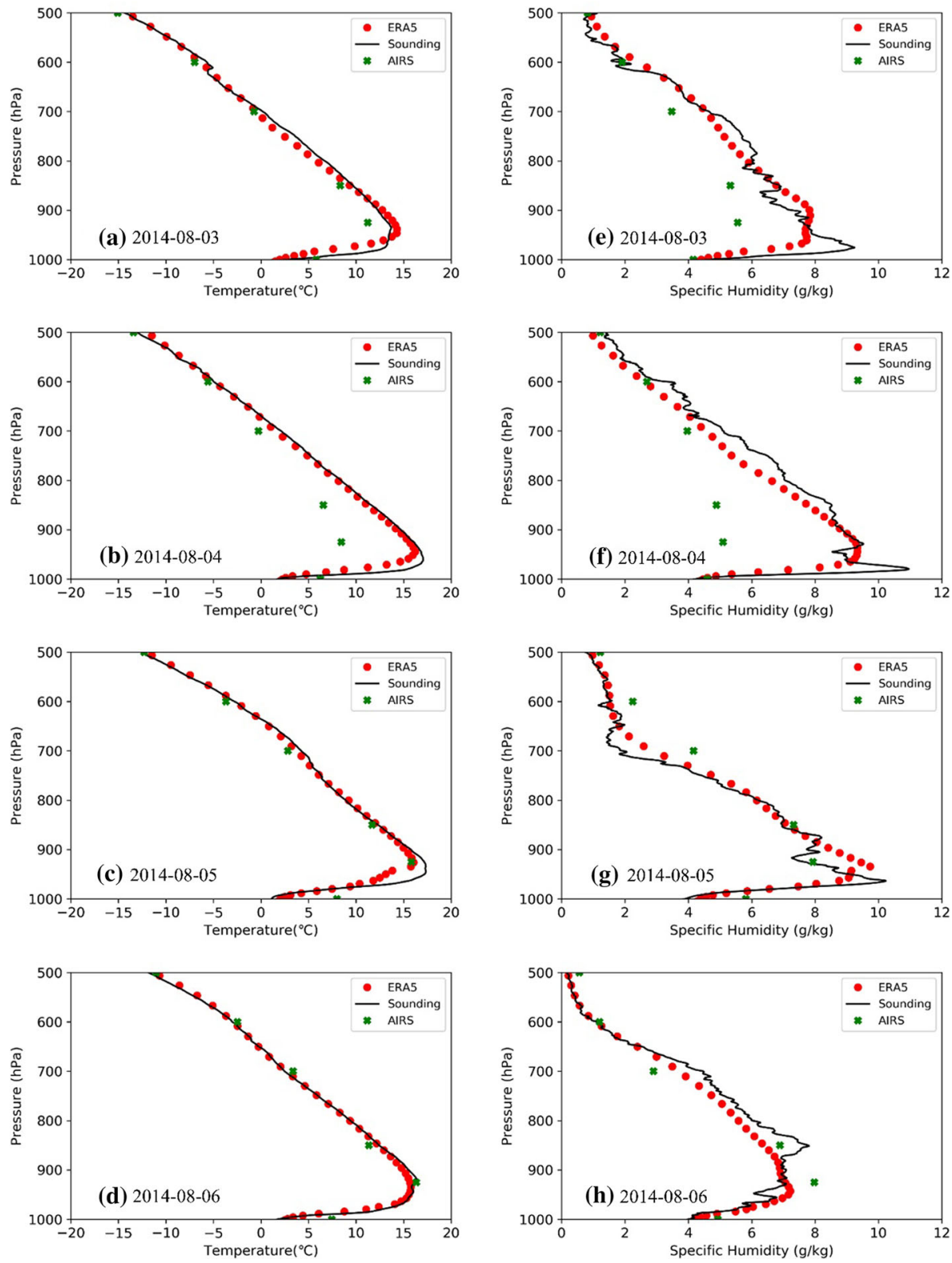

Fig. 4 Daily mean (a-d) temperature and $(\mathbf{e}-\mathbf{h})$ humidity profile from ERA5, AIRS and Soundings, from 3 to 6 August 2014, respectively 

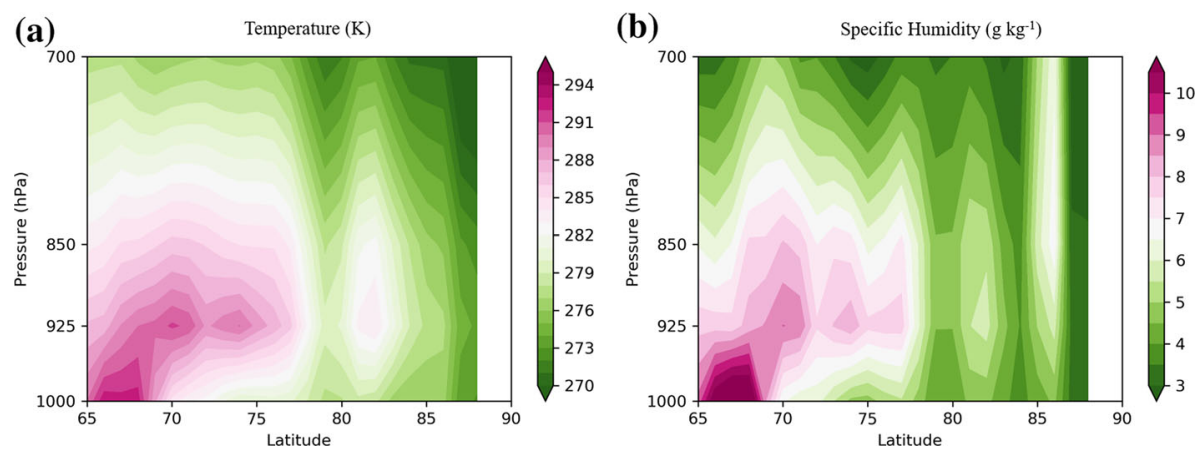

Fig. 5 Latitude-height cross-sections of (a) temperature $(\mathrm{K})$ and $(\mathbf{b})$ specific humidity $\left(\mathrm{g} \mathrm{kg}^{-1}\right)$ retrieved from AIRS
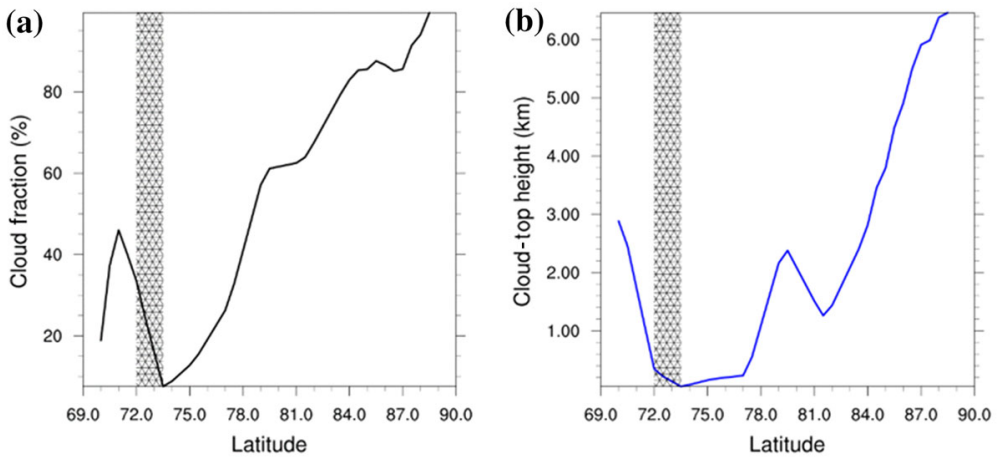

Fig. 6 CLARA (a) cloud fraction (\%) and (b) cloud top height $(\mathrm{km})$ along trajectories

been relatively accurate, but with a sharp surface inversion, a small temperature error in the satellite temperatures translate to a large error in cloud top.

\subsection{The Mean Structure of Moist and Warm Air Intrusion in ERA5}

Even though satellite observations can provide information on the mean state of the atmosphere, they cannot reveal process information related to turbulence or radiation. From ERA5, however, a multitude of diagnostics on temperature tendencies due to different physical processes are available, allowing a separation of the contribution from different physical processes, at least in the model.

The mean structure of the WaMAI from ERA5 is shown in Fig. 7. The flow of warm and moist air appears slanted up over the cold and dry air over the ice in a front-like structure (Fig. 7a, b), similar to the results in Komatsu et al. (2018). Consistent with the satellite observations, the near-surface temperature is dramatically reduced as the air travels poleward, especially when penetrating for over 2 days over the sea ice (Fig. 7a, b), where the surface temperature is near $0{ }^{\circ} \mathrm{C}$, diabatically constrained by the latent heat of melting. The crosssection of potential temperature (Fig. 7c) indicates a deepening well-mixed layer downstream. The depth of the well-mixed layer near the surface increased gradually from near zero at $70^{\circ} \mathrm{N}$ to over $400 \mathrm{~m}$ at $83^{\circ} \mathrm{N}$ (Fig. 7a, c). Interestingly, and in contrast to Komatsu et al. (2018), 

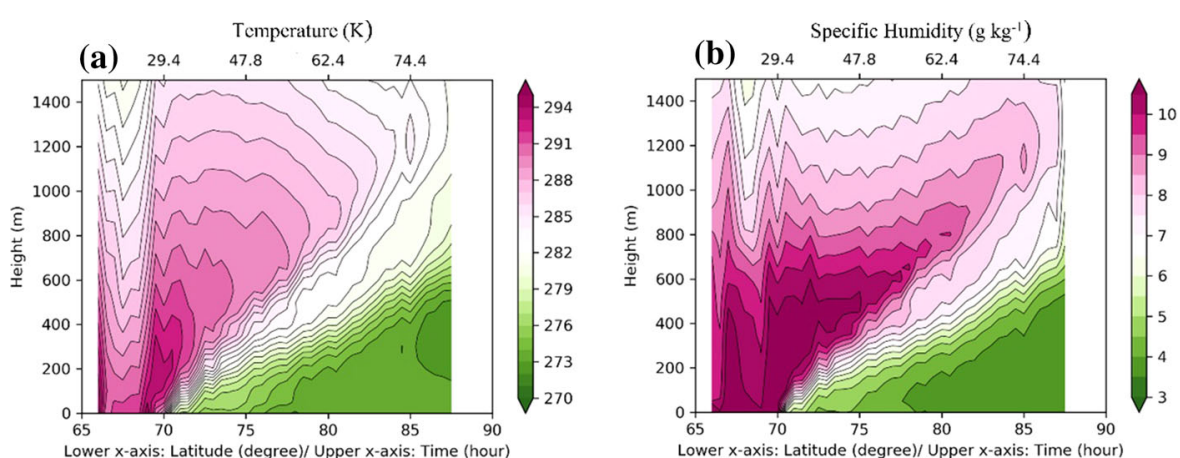

(c)

Potential Temperature $(\mathrm{K})$

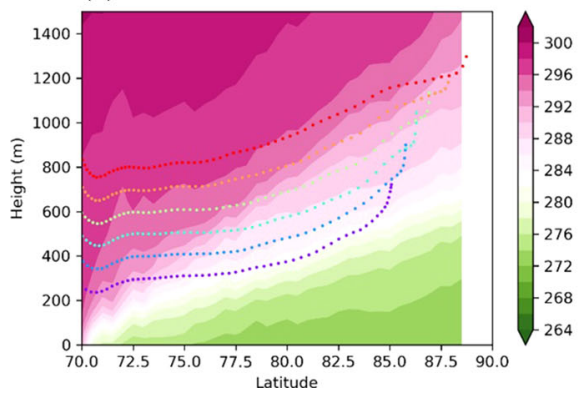

(d) Cloud Liquid Water Content $\left(\mathrm{g} \mathrm{kg}^{-1}\right)$

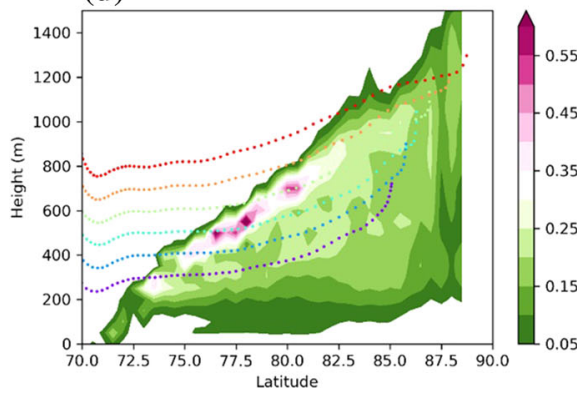

Fig. 7 Latitude-Height cross-sections of a temperature $(\mathrm{K})$, b specific humidity $\left(\mathrm{g} \mathrm{kg}^{-1}\right)$, $\mathbf{c}$ potential temperature $(\mathrm{K})$ and $\mathbf{d}$ cloud liquid water concentration $\left(\mathrm{g} \mathrm{kg}^{-1}\right)$ interpolated from ERA5 along trajectories. The coloured dots in (c), $\mathbf{d}$ are the trajectories, initiated from Oden's position, at the height of 300-800 m

while trajectories (Fig. 7d) tilt upward, their slope is less than that of the isentropic surfaces in Fig. 7c, and they also penetrate into the cloud layer. This indicates that the Komatsu et al. (2018) conclusion, that there is a warm-air upglide on top of the Arctic cold dome, does not represent the whole picture. Instead, the warm air is transformed by the sudden exposure to the new surface conditions, although some ascent is also present.

Farther north, the maximum temperature as well as specific humidity is found at increasingly higher altitude, and the signature of the WaMAI can be seen all the way to the end of the trajectories, although the distinction becomes increasingly diffuse. Around $77^{\circ} \mathrm{N}$ the strong single inversion splits up into two inversions in the model. As the warm air travels poleward, the altitudes of both inversions increase but the upper inversion has a larger slope (Fig. 7a). The temperature aloft decreases, likely due to longwave radiative cooling to space, while specific humidity aloft decreases, likely by entrainment into the boundary layer followed by cloud formation and release of precipitation.

Fog is formed slightly north of $70^{\circ} \mathrm{N}$, with a top around 100-200 m (Fig. 7d) and stays up to $72.5^{\circ} \mathrm{N}$. Hence, the fog lifts to low clouds somewhat more rapidly than in the observations (see Oden's location in Fig. 4). The thickness of the cloud layer increases downstream, while the cloud top gradually ascends almost linearly, reaching $1 \mathrm{~km}$ at $83^{\circ} \mathrm{N}$. The boundary-layer depth, as diagnosed in ERA5, and liquid-water path (Fig. 8a, c) increase almost all the way to the end of the trajectory. The main cloud layer remains associated with the upper inversion while the boundary-layer depth is associated with the lower inversion. This type of stratification, commonly known as cloud decoupling, is quite common in the Arctic (Shupe et al. 2013; Sotiropoulou et al. 2014; Brooks et al. 2017). Precipitation (Fig. 8d) also starts 

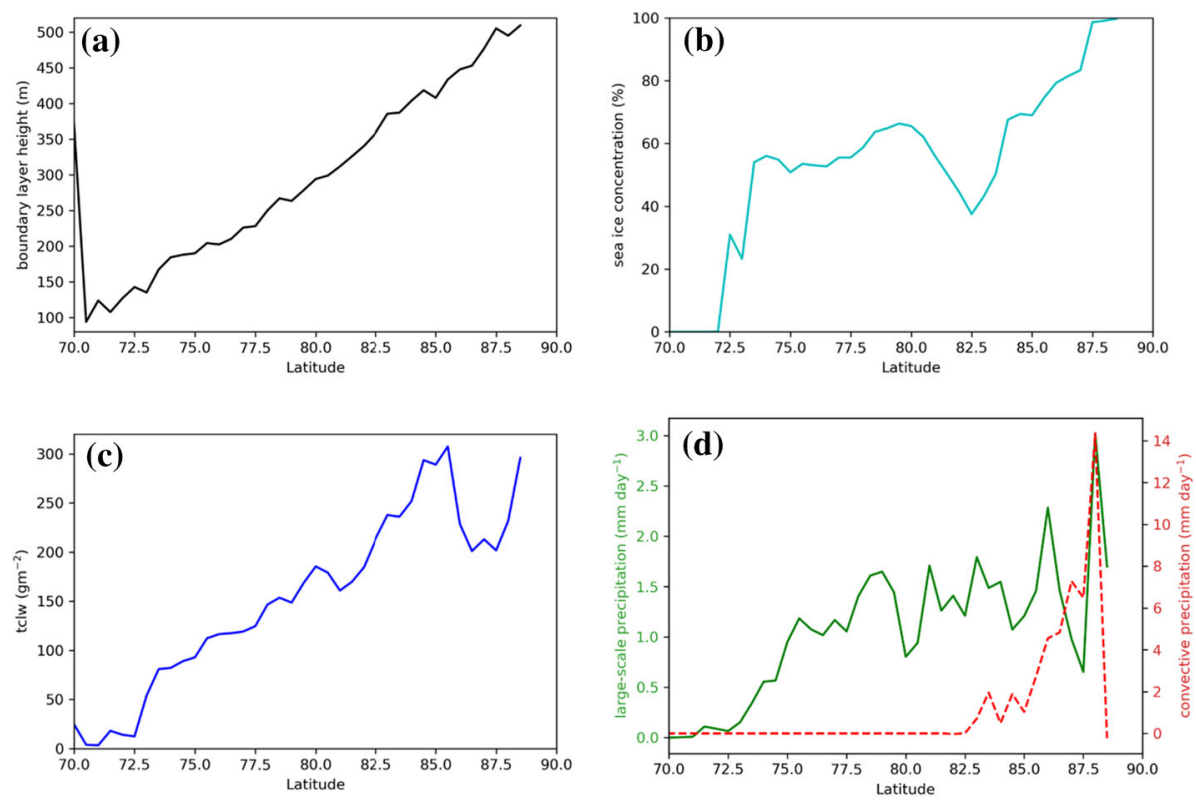

Fig. 8 Several parameters analyzed from ERA5: a boundary-layer height (m), b sea-ice concentration (\%), $\mathbf{c}$ liquid-water path $\left(\mathrm{g} \mathrm{m}^{-2}\right)$ and $\mathbf{d}$ precipitation $\left(\mathrm{mm} \mathrm{day}^{-1}\right)$ divided into (green) large-scale and (red dashed) convective averaged along the trajectories

at the ice edge and increases until to about $79^{\circ} \mathrm{N}$, entirely made up by so-called large-scale precipitation, in reality most likely drizzle or frozen drizzle, which is also common in the summer Arctic. North of $79^{\circ} \mathrm{N}$ it becomes quasi-constant but north of $82^{\circ} \mathrm{N}$ there is a rapid increase of convective precipitation.

Generally, there are both similarities and differences between the satellite observations and ERA5. In principle, both show that warm and moist air is penetrating poleward over sea ice and adapting to the new surface conditions. The boundary layer deepens in both datasets and becomes more and more well mixed, supporting the hypothesis of Tjernström et al. (2019). The most notable difference, however, between AIRS and ERA5 is the spatial structure of the boundary-layer growth. The ERA5 boundary-layer growth is more or less linear all the way to the end of the trajectories and its top ends up around $1 \mathrm{~km}$, while the AIRS boundary layer grows much faster initially but rolls off to a quasi-constant height of $925 \mathrm{hPa}$, roughly $700 \mathrm{~m}$, already around $74^{\circ} \mathrm{N}$. A second difference is the split of the inversion in ERA5, where the upper inversion ascends faster than the lower one forming a decoupled cloud system. AIRS indicates that the clouds might dissipate in the high Arctic, and the inversion disappears, while ERA5 instead indicates the clouds thicken and convection becomes more active; except in frontal systems convection is very rare over the Arctic sea ice.

\subsection{The Atmospheric Energy Budget of Moist and Warm Air Intrusions}

All terms in the thermal energy equation (Eq. 3) are evaluated along the trajectories with the method introduced in Sect. 2.2 (Fig. 9). The temperature tendency due to all parametrized physics in the model (Fig. 9a) generally cools the boundary layer, especially in the inversions, with a slight warming inside the more well-mixed portions of the boundary layer. The 
(a) Temperature Tendency

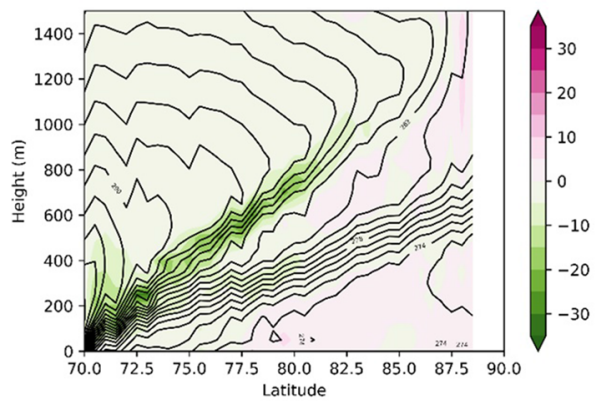

(c) Longwave Radiative Heat

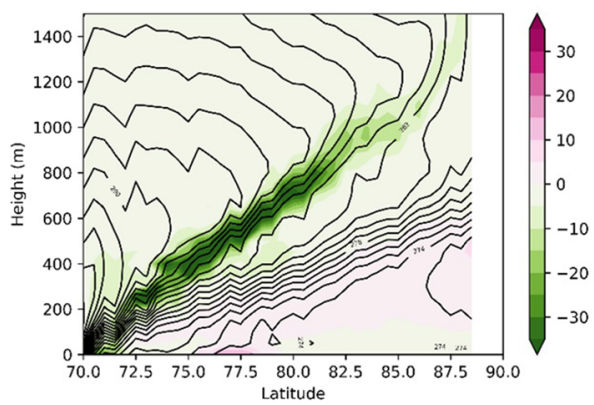

(e) Turbulent Sensible and Latent Heat

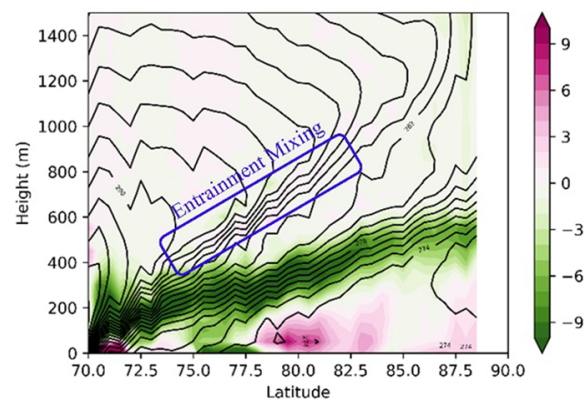

(b) Temperature Advection

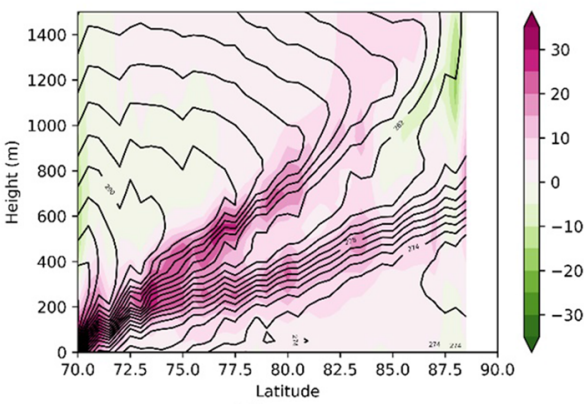

(d) Latent Heat

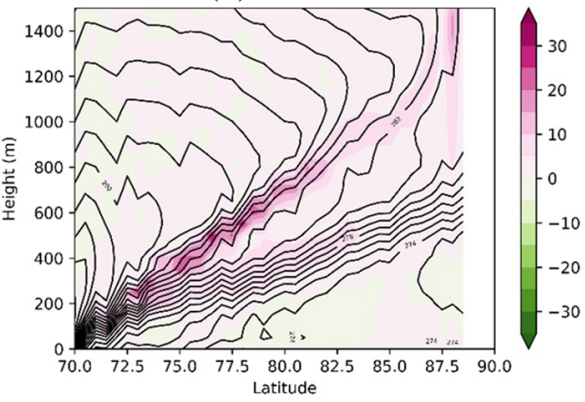

(f) Shortwave Radiative Heat

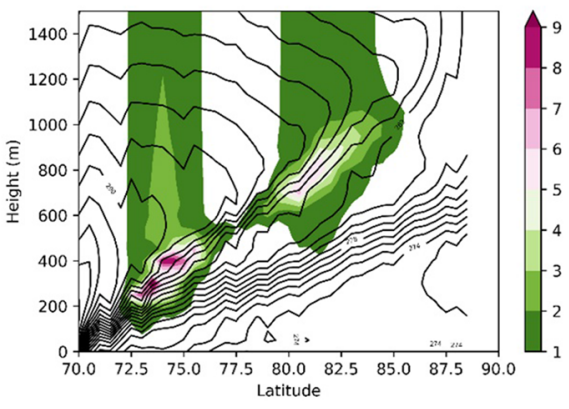

Fig. 9 Latitude-height cross-sections of ERA5 a temperature tendency due to model physics, b temperature advection, $\mathbf{c}$ longwave radiative heating, $\mathbf{d}$ latent heating, $\mathbf{e}$ turbulent heat, and $\mathbf{f}$ shortwave radiative heating along the trajectories, all in $\mathrm{K} \mathrm{day}^{-1}$. Black solid contours in in all panels are the mean temperature isolines

maximum local cooling rates reaches $30 \mathrm{~K} \mathrm{day}^{-1}$ inside the inversion. This is, to a first degree, balanced by temperature advection (Fig. 9b), indicating both that the situation is quasi-stationary and that there is a gradual transformation of the air mass. For completeness, the moisture advection is also shown in Fig. $10 \mathrm{a}$. Until $83^{\circ} \mathrm{N}$, the latter shows great structural similarity to the temperature advection (Fig. 9b), however, farther north there is a strong moistening of the air aloft, above the inversion, which is possibly connected to the initiation of convective precipitation seen in Fig. 8d.

In the upper inversion, there is a large longwave radiative cooling which consequently cools mainly the top of the upper cloud layer by 30-40 $\mathrm{K} \mathrm{day}^{-1}$ (Fig. 9c). Longwave radiation trapped below clouds simultaneously warms the layer below the lower inversion slightly, due 
(a) Moisture Advection

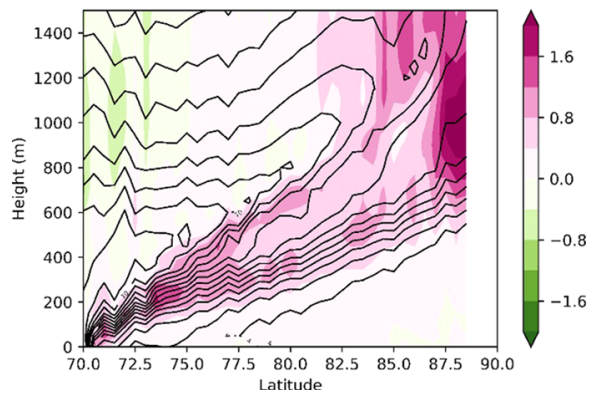

(b) Temperature Advection $+T_{-}$tendency

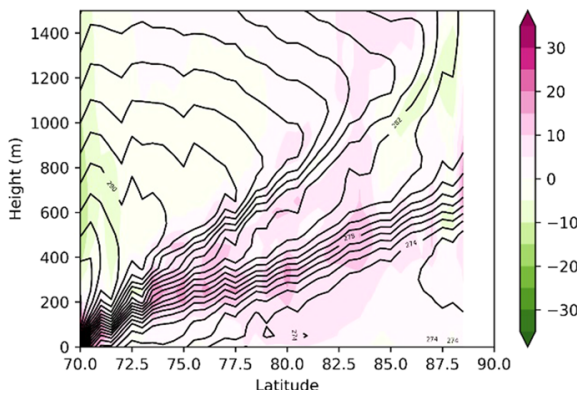

Fig. 10 Same as Fig. 9 but for a moisture advection $\left(\mathrm{g} \mathrm{kg}^{-1} \mathrm{day}^{-1}\right),(\mathbf{b})$ temperature advection + temperature tendency due to model physics $\left(\mathrm{K}\right.$ day $\left.^{-1}\right)$, along the trajectories. Black contours represent temperature $(\mathrm{K})$ in (b) and specific humidity in (a)

to the greenhouse effect of the clouds. This strong cooling contributes to intensifying the vertical temperature gradients at cloud top (Fig. 9a).

Entrainment mixes warmer and moister air from aloft down into the boundary layer where it is cooled and saturated, contributing to the growth of clouds, the increasing altitude of the cloud top, precipitation, and the release of latent heat. This entrainment mixing is highlighted with a blue quadrilateral in Fig. 9e. Hence, in the cloud, water vapour condensation releases latent heat that caused a local warming of around $10-20 \mathrm{~K} \mathrm{day}^{-1}$, larger than expected, possibly due to the very large supply of water vapour being mixed in from the air aloft (Fig. 9d). This partly offset the longwave radiative cooling. The upper cloud layer also absorbed shortwave radiation (Fig. 9f). However, the shortwave radiative heating is much smaller than both the longwave radiative cooling and the latent heating $\left(<10 \mathrm{~K} \mathrm{day}^{-1}\right)$ (Fig. 9f).

The temperature tendency due to the vertical divergence of turbulent heat flux is also small, $< \pm 10 \mathrm{~K} \mathrm{day}^{-1}$ (Fig. 9e). It has the largest impact in the lower inversion where it is a cooling factor while the air nearest to the ground is slightly warmed. As the boundarylayer depth increases and the layer below the inversion becomes more and more well-mixed, warmer air is drawn down from the inversion to the surface, thereby cooling the layer in the inversion and warming the lower boundary layer.

\subsection{The Surface Energy Budget Below the Moist and Warm Air Intrusions}

In summer, the surface energy budget is expected to be positive over much of the Arctic Ocean which is indeed why the sea-ice is decreasing. At this time of the year, early August, clouds over sea ice with a sufficiently high albedo usually warm the surface (Sedlar et al. 2011) compared to clear conditions, which is known as a positive cloud radiative effect. Tjernström et al. $(2015,2019)$ argues that in a WaMAIs we expect an additional surface warming, caused by the sum of the additional net surface longwave radiation, from the warmer than usual high-emissivity cloudy air, and the downward turbulent heat flux overwhelming the expected deficit net surface solar radiation due to the low clouds.

In the following, we define a surface flux as positive when directed towards the surface. Along the WaMAI trajectories, the anomalies of turbulent surface sensible (sshf), latent heat fluxes (slhf), and the net thermal radiation (str) turned to be positive (Fig. 11a). The anomalies of sshf and slhf change abruptly already over the open water, while the net thermal radiation 

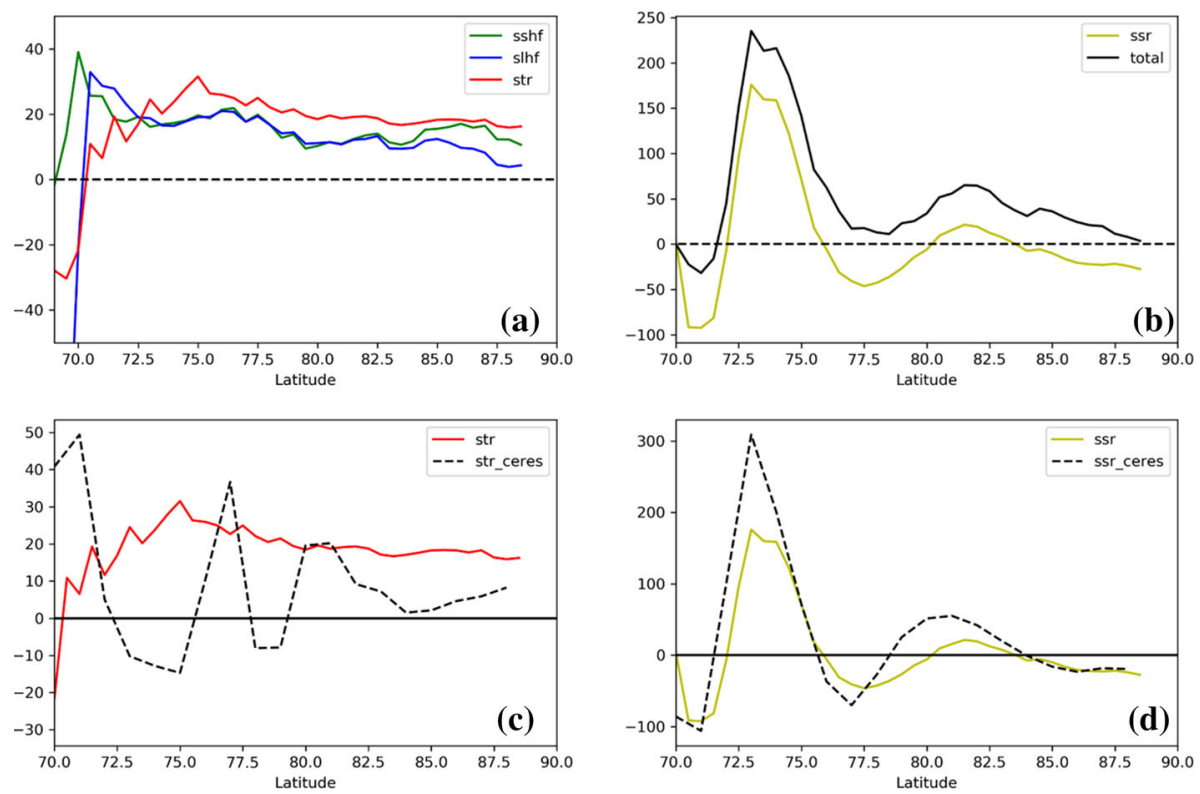

Fig. 11 (a) surface sensible heat flux (sshf, green line), surface latent heat flux (slhf, blue line) and surface net thermal radiation (str, red line) along the trajectories. (b) surface net shortwave radiation (ssr, yellow line) and surface total energy budget (black line) along the trajectories. (c) surface net thermal radiation (str, red line) in ERA5 and its counterpart in CERES product (black dash line). (d) surface solar radiation (ssr, yellow line) in ERA5 and its counterpart in CERES product (black dash line). The unit is $\mathrm{J} \mathrm{m}^{-2}$ in all figures

changes more gradually. All of them remain positive to the end of the trajectories. The anomaly of net solar radiation (ssr) has two large positive signals near the ice edge and near $81^{\circ} \mathrm{N}$, respectively. These large signals may only happen with a deficit in cloudiness; in fact, the median of the estimated shortwave cloud-radiative effect from the Oden observations is only $-50 \mathrm{Wm}^{-2}$, and losing all the clouds would increase the surface net shortwave radiation by only $20-100 \mathrm{Wm}^{-2}$ (not shown). This would also be inconsistent with the liquid-water path in Fig. 8c, which is of the same order of magnitude as the observation on Oden. As the clouds in the model continuously grow optically thicker from $72.5^{\circ} \mathrm{N}$, less and less shortwave radiation can pass through the clouds, while from $78.5^{\circ} \mathrm{N}$ clouds started to lose more cloud water by more large-scale precipitation (Fig. 8c, d), and more solar radiation can reach the surface again (Fig. 11b). Combining all the terms in the surface energy budget, the net results shows a strong positive anomaly at $72-76^{\circ} \mathrm{N}$, and remains positive to the end of the trajectory although with a weaker local maximum around $82^{\circ} \mathrm{N}$. Solar radiation in the CERES satellite product (ssr_ceres) has a tendency similar to ERA5 but is even higher (Fig. 11d). Longwave radiation in CERES (str_ceres) is, however, very different from that in ERA5. Generally, in this MaWAI, positive turbulence heat fluxes and net thermal radiation contribute to the positive net surface energy budget anomaly.

\section{Conclusion}

In this paper, we have developed a methodology in the spirit of Pithan et al. (2018), allowing us to follow an air mass and identify its development when warm and moist air traverses 
Longwave Cooling $\rightarrow$ Entrainment Mixing $\rightarrow$ Clouds Grow $\rightarrow$ Elevated Cloud Top

$\rightarrow$ Elevated upper Inversion $\rightarrow$ Double Inversion

Turbulent Mixing $\rightarrow$ Elevated Lower Inversion $\rightarrow$ Deepened Well-mixed Layer
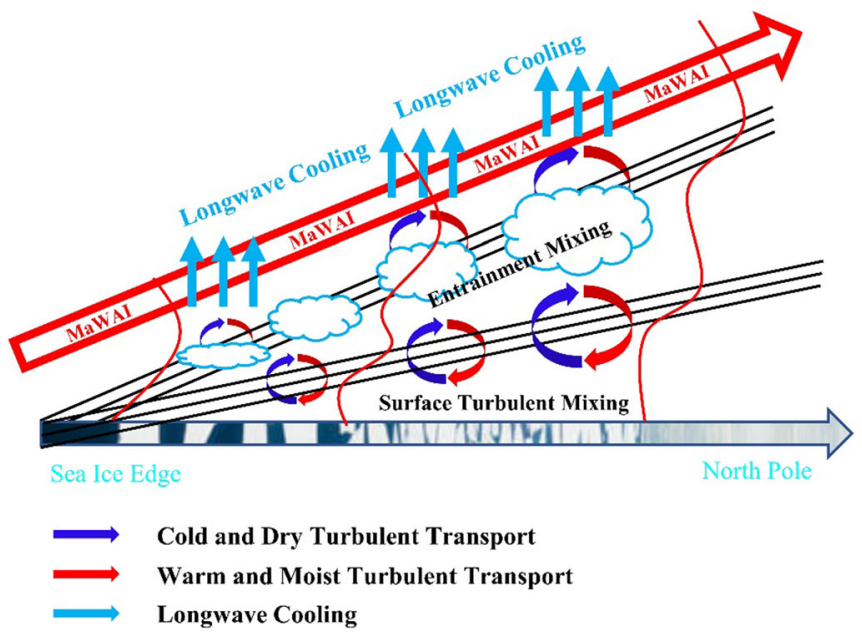

Fig. 12 Conceptual graph for the warm-air-mass transmission over melting sea-ice

northward. Figure 12 encapsulates our results. The boundary layer is transformed from a stably stratified surface inversion into a well-mixed layer by surface turbulent mixing while the upper layer develops with strong cloud-top cooling. Both layers grow in thickness as the MaWAI penetrates farther into Arctic. Entrainment at cloud top contributed to the growth of clouds by transporting warmer air and moisture into the cloud. As clouds grow, the cl top ascends and the inversion is eventually separated into two - each with a relatively well-mixed layer below. The changes in the air column as it moves northward are balanced by advection from the south, and the situation is nearly stationary on the time scale of a few days.

We try to answer the two questions posed in the Introduction.

1. What happens even farther downstream; will the surface inversion erode and give way to a shallow cloud-capped well-mixed boundary layer as hypothesized?

Although the vertical structure is slightly different in AIRS and ERA5, both indicate that the surface inversion is eroded and gives place for a well-mixed boundary layer as the air travels north over the sea ice, offering support to the hypothesis. Although trajectories ascend northward, there is no "upglide over the cold polar dome" as previously suggested. The ERA5 development, with the split into a decoupled stratocumulus, is plausible, and multiple evidence suggest that decoupled clouds are common in the Arctic; however, this structure is not present in AIRS even if satellite data are essentially the only information assimilated at the highest latitudes. The WaMAI anomalies in ERA5 remain all the way to the end of the trajectory calculations. It is contrary to the hypothesis formulated in Tjernström et al. (2019), which assumes that the transformation of the air would relax back to climatology. In hindsight, this hypothesis unfairly compares the central Arctic climatology to the near ice-edge extremes. In summary, more work is needed to understand the far effects of WaMAIs on the high Arctic. 
2. The observed surface inversion near the ice edge was quasi-stationary for about a week; what boundary-layer or larger-scale processes are mainly responsible for maintaining this very robust feature?

The analysis of ERA5 shows that temperature tendency due to turbulent, radiative, and phase-transition effects is mostly balanced by temperature advection, for an almost stationary case. The dominating terms in the thermal budget of the atmosphere are warm-air advection and longwave radiative cooling, as was previously expected (e.g., Tjernström et al. 2015). However, the release of latent heat during cloud formation contributes substantially and is the largest secondary effect, while shortwave radiation and turbulent heat-flux divergence play minor roles.

We have suggested a method for taking studies of warm and moist intrusions, or Arctic atmospheric rivers, from the common Eulerian framework to Lagrangian setting, and have illustrated the usefulness of combining field observations with routine satellite observations and reanalysis. We have found that this is not straightforward since both the satellite observations and the model used in the reanalysis have their own set of shortcomings in the central Arctic and more air-mass-transformation studies are necessary for a better understanding of WaMAIs.

There is also a need for more detailed observations of such events. Field campaigns need to start considering the Lagrangian description of developing atmospheric processes, possibly using aircraft tracking and revisiting the same air mass multiple times in a way that has not happened much since the Atlantic Stratocumulus Transition Experiment (ASTEX) (Albrecht et al. 1995) or the Aerosol Characterization Experiment (ACE) (Bates et al. 1998).

Acknowledgements This research was supported by the Swedish Research Council. The ERA5 data was downloaded from www.ecmwf.int/en/forecasts/datasets/reanalysis-datasets/era5, the AIRS data from https://earthdata.nasa.gov/earth-observation-data/near-real-time/download-nrt-data/airs-nrt and the CERES data from https://ceres.larc.nasa.gov/data/. The authors are grateful to the ACSE project for providing the data from Oden (available at www.bolin.su.se/data) and to Cian Woods for providing the trajectory calculation algorithm.

Funding Open access funding provided by Stockholm University.

Open Access This article is licensed under a Creative Commons Attribution 4.0 International License, which permits use, sharing, adaptation, distribution and reproduction in any medium or format, as long as you give appropriate credit to the original author(s) and the source, provide a link to the Creative Commons licence, and indicate if changes were made. The images or other third party material in this article are included in the article's Creative Commons licence, unless indicated otherwise in a credit line to the material. If material is not included in the article's Creative Commons licence and your intended use is not permitted by statutory regulation or exceeds the permitted use, you will need to obtain permission directly from the copyright holder. To view a copy of this licence, visit http://creativecommons.org/licenses/by/4.0/.

\section{References}

Albrecht BA, Bretherton CS, Johnson D, Schubert WH, Frisch AS (1995) The Atlantic Stratocumulus Transition Experiment-ASTEX. Bull Am Meteorol Soc 76:889-904. https://doi.org/10.1175/1520-0477(1 995)076\%3c0889:TASTE\%3e2.0.CO;2

Bates TS, Huebert BJ, Gras JL, Griffiths FB, Durkee PA (1998) International Global Atmospheric Chemistry (IGAC) Project's First Aerosol Characterization Experiment (ACE 1): overview. J Geophys Res Atmos 103:16297-16318

Brooks IM, Tjernström M, Persson POG, Shupe MD, Atkinson RA, Canut G, Birch CE, Mauritsen T, Sedlar J, Brooks BJ (2017) The turbulent structure of the Arctic summer boundary layer during the Arctic summer cloud-ocean study. J Geophys Res Atmos 122:9685-9704. https://doi.org/10.1002/2017JD027234 
Chahine MT, Pagano TS, Aumann HH, Atlas R, Barnet C, Blaisdell J, Chen L, Divakarla M, Fetzer EJ, Goldberg M, Gautier C, Granger S, Hannon S, Irion FW, Kakar R, Kalnay E, Lambrigtsen BH, Lee SY, Le Marshall J, Mcmillan W, Mcmillin L, Olsen ET, Revercomb H, Rosenkranz P, Smith WL, Staelin D, Strow LL, Susskind J, Tobin D, Wolf W, Zhou L (2006) Improving weather forecasting and providing new data on greenhouse gases. Bull Am Meteorol Soc 87:911-926. https://doi.org/10.1175/BAMS-87$7-911$

Cohen J, Screen JA, Furtado JC, Barlow M, Whittleston D, Coumou D, Francis J, Dethloff K, Entekhabi D, Overland J, Jones J (2014) Recent Arctic amplification and extreme mid-latitude weather. Nat Geosci 7:627-637

Derksen C, Brown R (2012) Spring snow cover extent reductions in the 2008-2012 period exceeding climate model projections. Geophys Res Lett 39:L19504. https://doi.org/10.1029/2012GL053387

Devasthale A, Sedlar J, Kahn BH, Tjernström M, Fetzer EJ, Tian B, Teixeira J, Pagano TS (2016) A decade of spaceborne observations of the Arctic atmosphere novel insights from NASA's airs instrument. Bull Am Meteorol Soc 97:2163-2176. https://doi.org/10.1175/BAMS-D-14-00202.1

Francis JA, Vavrus SJ (2012) Evidence linking Arctic amplification to extreme weather in mid-latitudes. Geophys Res Lett. https://doi.org/10.1029/2012GL051000

Graversen RG, Mauritsen T, Tjernström M, Källén E, Svensson G (2008) Vertical structure of recent Arctic warming. Nature 451:53-56. https://doi.org/10.1038/nature06502

Hersbach H, Bell B, Berrisford P, Hirahara S, Horányi A, Muñoz-Sabater J, Nicolas J, Peubey C, Radu R, Schepers D, Simmons A, Soci C, Abdalla S, Abellan X, Balsamo G, Bechtold P, Biavati G, Bidlot J, Bonavita M, De Chiara G, Dahlgren P, Dee D, Diamantakis M, Dragani R, Flemming J, Forbes R, Fuentes M, Geer A, Haimberger L, Healy S, Hogan RJ, Holm E, Janiskova M, Keeley S, Laloyaux P, Lopez P, Lupu C, Radnoti R, Rosnay P, Rozum I, Vamborg F, Villaume S, Thepaut JN (2020) The ERA5 global reanalysis. Q J R Meteorol Soc 146:1999-2049. https://doi.org/10.1002/qj.3803

Johansson E, Devasthale A, Tjernström M, Ekman AML, L'Ecuyer T (2017) Response of the lower troposphere to moisture intrusions into the Arctic. Geophys Res Lett 44:2527-2536. https://doi.org/10.1002/2017GL0 72687

Kapsch ML, Graversen RG, Tjernström M (2013) Springtime atmospheric energy transport and the control of Arctic summer sea-ice extent. Nat Clim Chang 3:744-748. https://doi.org/10.1038/nclimate1884

Kapsch ML, Graversen RG, Tjernström M, Bintanja R (2016) The effect of downwelling longwave and shortwave radiation on Arctic summer sea ice. J Clim 29:1143-1159. https://doi.org/10.1175/JCLI-D-1 5-0238.1

Karlsson KG, Anttila K, Trentmann J, Stengel M, Fokke-Meirink J, Devasthale A, Hanschmann T, Kothe S, Jaäskelaïnen E, Sedlar J, Benas N, van Zadelhoff GJ, Schlundt C, Stein D, Finkensieper S, Häkansson N, Hollmann R (2017) CLARA-A2: The second edition of the CM SAF cloud and radiation data record from 34 years of global AVHRR data. Atmos Chem Phys 17:5809-5828

Komatsu KK, Alexeev VA, Repina IA, Tachibana Y (2018) Poleward upgliding Siberian atmospheric rivers over sea ice heat up Arctic upper air. Sci Rep. https://doi.org/10.1038/s41598-018-21159-6

Lawrence DM, Slater AG, Tomas RA, Holland MM, Deser C (2008) Accelerated Arctic land warming and permafrost degradation during rapid sea ice loss. Geophys Res Lett. https://doi.org/10.1029/2008GL03 3985

Liu Y, Key JR, Vavrus S, Woods C (2018) Time evolution of the cloud response to moisture intrusions into the Arctic during Winter. J Clim 31:9389-9405. https://doi.org/10.1175/JCLI-D-17-0896.1

Messori G, Woods C, Caballero R (2018) On the drivers of wintertime temperature extremes in the high Arctic. J Clim 31:1597-1618. https://doi.org/10.1175/JCLI-D-17-0386.1

Naakka T, Nygård T, Vihma T, Sedlar J, Graversen R (2019a) Atmospheric moisture transport between midlatitudes and the Arctic: regional, seasonal and vertical distributions. Int J Climatol 39:2862-2879. https:// doi.org/10.1002/joc.5988

Naakka T, Nygård T, Tjernström M, Vihma T, Pirazzini R, Brooks IM (2019b) The impact of radiosounding observations on numerical weather prediction analyses in the Arctic. Geophys Res Lett 46:8527-8535. https://doi.org/10.1029/2019GL083332

Pithan F, Svensson G, Caballero R, Chechin D, Cronin TW, Ekman AML, Neggers R, Shupe MD, Solomon A, Tjernström M, Wendisch M (2018) Role of air-mass transformations in exchange between the Arctic and mid-latitudes. Nat Geosci 11:805-812

Sedlar J, Shupe MD, Tjernström M (2012) On the relationship between thermodynamic structure and cloud top, and its climate significance in the Arctic. J Clim 25:2374-2393. https://doi.org/10.1175/JCLI-D-1 1-00186.1

Sedlar J, Tjernström M, Mauritsen T, Shupe MD, Brooks IM, Persson POG, Birch CE, Leck C, Sirevaag A, Nicolaus M (2011) A transitioning Arctic surface energy budget: the impacts of solar zenith angle, 
surface albedo and cloud radiative forcing. Clim Dyn 37:1643-1660. https://doi.org/10.1007/s00382-01 0-0937-5

Serreze MC, Francis JA (2006) The Arctic amplification debate. Clim Change 76:241-264. https://doi.org/1 $0.1007 / \mathrm{s} 10584-005-9017-\mathrm{y}$

Shupe MD, Persson POG, Brooks IM, Tjernström M, Sedlar J, Mauritsen T, Sjogren S, Leck C (2013) Cloud and boundary layer interactions over the Arctic sea ice in late summer. Atmos Chem Phys 13:9379-9400. https://doi.org/10.5194/acp-13-9379-2013

Simmonds I (2015) Comparing and contrasting the behaviour of Arctic and Antarctic sea ice over the 35 year period 1979-2013. Ann Glaciol 56:18-28. https://doi.org/10.3189/2015AoG69A909

Sotiropoulou G, Sedlar J, Forbes R, Tjernström M (2016) Summer Arctic clouds in the ECMWF forecast model: an evaluation of cloud parametrization schemes. Q J R Meteorol Soc 142:387-400. https://doi. org/10.1002/qj.2658

Sotiropoulou G, Sedlar J, Tjernström M, Shupe MD, Brooks IM, Persson POG (2014) The thermodynamic structure of summer Arctic stratocumulus and the dynamic coupling to the surface. Atmos Chem Phys 14:12573-12592. https://doi.org/10.5194/acp-14-12573-2014

Sotiropoulou G, Tjernström M, Savre J, Ekman AML, Hartung K, Sedlar J (2018) Large-eddy simulation of a warm-air advection episode in the summer Arctic. Q J R Meteorol Soc 144:2449-2462. https://doi.org/ 10.1002/qj.3316

Susskind J, Blaisdell JM, Iredell L (2014) Improved methodology for surface and atmospheric soundings, error estimates, and quality control procedures: the atmospheric infrared sounder science team version-6 retrieval algorithm. J Appl Remote Sens. https://doi.org/10.1117/1.jrs.8.084994

Tedesco M, Fettweis X, Mote T, Wahr J, Alexander P, Box JE, Wouters B (2013) Evidence and analysis of 2012 Greenland records from spaceborne observations, a regional climate model and reanalysis data. Cryosph 7:615-630. https://doi.org/10.5194/tc-7-615-2013

Tjernström M (2005) The summer Arctic boundary layer during the Arctic Ocean Experiment 2001 (AOE2001). Boundary-Layer Meteorol 117:5-36. https://doi.org/10.1007/s10546-004-5641-8

Tjernström M, Birch CE, Brooks IM, Shupe MD, Persson POG, Sedlar J, Mauritsen T, Leck C, Paatero J, Szczodrak M, Wheeler CR (2012) Meteorological conditions in the central Arctic summer during the Arctic Summer Cloud Ocean Study (ASCOS). Atmos Chem Phys 12:6863-6889. https://doi.org/10.51 94/acp-12-6863-2012

Tjernström M, Shupe MD, Brooks IM, Persson POG, Prytherch J, Salisbury DJ, Sedlar J, Achtert P, Brooks BJ, Johnston PE, Sotiropoulou G, Wolfe D (2015) Warm-air advection, air mass transformation and fog causes rapid ice melt. Geophys Res Lett 42:5594-5602. https://doi.org/10.1002/2015GL064373

Tjernström M, Shupe MD, Brooks IM, Achtert P, Prytherch J, Sedlar J (2019) Arctic summer airmass transformation, surface inversions, and the surface energy budget. J Clim 32:769-789. https://doi.org/10.117 5/JCLI-D-18-0216.1

Vihma T (2014) Effects of Arctic sea ice decline on weather and climate: a review. Surv Geophys 35:1175-1214. https://doi.org/10.1007/s10712-014-9284-0

Wielicki BA, Barkstrom BR, Harrison EF, Lee RB, Smith GL, Cooper JE (1996) Clouds and the earth's radiant energy system (CERES): an earth observing system experiment. Bull Am Meteorol Soc 77:853-868. https://doi.org/10.1175/1520-0477(1996)077\%3c0853:CATERE\%3e2.0.CO;2

Woods C, Caballero R (2016) The role of moist intrusions in winter Arctic warming and sea ice decline. J Clim 29:4473-4485. https://doi.org/10.1175/JCLI-D-15-0773.1

Woods C, Caballero R, Svensson G (2013) Large-scale circulation associated with moisture intrusions into the Arctic during winter. Geophys Res Lett 40:4717-4721. https://doi.org/10.1002/grl.50912

Publisher's Note Springer Nature remains neutral with regard to jurisdictional claims in published maps and institutional affiliations. 